\title{
Öğrenci Velilerinin Özel Okullardan Memnuniyet Düzeylerinin Yapısal Eşitlik Modeli ile Değerlendirilmesi
}

\author{
Süleyman ALPAYKUT ${ }^{1}$
}

$\ddot{O} z$

Son yıllarda özel okul sayısında yaşanan artış ve velilerin okul seçiminde daha seçici davranması sonucu, sektörde rekabet artmıştır. Bu durum, okulların veli memnuniyeti açısından dikkat etmeleri gereken faktörleri belirlemelerini gerekli kılmaktadır. Bu çalışmada, İmir'de ě̆itim veren özel bir ilköğretim okulunda okuyan ögrencilerin velilerinin okuldan memnuniyet düzeylerini ölçmek amacıyla yapılan araştırma sonuçları paylaşılmıştır. Yapılan anket sonucu elde edilen veriler analiz edilmiş, faktörlere ayrılmış ve daha sonra Yapısal Eşitlik Modeli (YEM) kullanılarak faktörlerin ăgırlıkları belirlenmiştir. Analiz sonuçlarına göre, ögrenci velileri, okulların sahip olduğu teknolojik imkanları ve yemekhane imkanlarını, ögrencilerin eğitim aldıklarl sınıfların durumundan ve ögrencilere verilen ödev ve projelerden daha önemli bulunmuştur.

Anahtar Kelimeler: Yapısal Eşitlik Modeli, Özel Okul, Veli Memnuniyeti.

JEL Sinıflandırma Kodları: C1, C3, C4.

\section{Evaluation of Student Parent's Satisfaction Levels from Fee-Paying Schools by Structural Equation Modeling}

\begin{abstract}
In recent years, as a result of the increase in the number of fee-paying schools and the parents' selective behaviors with regard to school selection, the rivalry in this sector has increased. This circumstance necessitates the determination of factors that need to be paid attention in terms of parent satisfaction, by the schools. In this study, the results of the research aiming the measurement of the levels of parents' satisfaction from a fee-paying elementary school giving education in Izmir are shared. The data gathered from questionnaire conducted were analyzed, decomposed into factors, and then the weights of factors were determined by using Structural Equation Modeling (SEM). According to the results of analysis, by the parents, the technological opportunities and cafeteria facilities were considered more significant than the classroom conditions, homework and projects given to the students.
\end{abstract}

Keywords: Structural Equation Modeling, Fee-Paying Schools, Parent's Satisfaction.

JEL Classification Codes: C1, C3, C4.

\footnotetext{
${ }^{1}$ Doç. Dr., Dokuz Eylül Üniversitesi, İstatistik Bölümü, s.alpaykut@deu.edu.tr
} 


\section{GİRIŞ}

\section{S.ALPAYKUT}

Yapısal Eşitlik Modeli (YEM) (Structural Equation Modeling-SEM), açık (gözlenen, ölçülen) ve gizil (latent) (gizli, gözlenemeyen, ölçülemeyen) değişkenler arasındaki nedensel (causal) ve korelasyonel ilişkilerin bir arada bulunduğu modellerin test edilmesinde kullanılan kapsamlı bir istatistik yaklaşımdır (Hoyle, 1995: 158-177). YEM, gizil değişkenler seti arasında bir nedensellik yapısının var olduğunu ve gizil değişkenlerin gözlenen değişkenler aracılığıyla ölçülebildiği varsayımına dayanmaktadır (Yılmaz, 2004).

Gizil değişkenler YEM'in en önemli kavramlarından biridir ve araştırmacıların gerçekte ilgilendikleri zeka, güdü, duygu, tutum gibi soyut kavramlara ya da psikolojik yapılara karşılık gelir. Bu yapılar ancak dolaylı olarak belirli davranışlar ya da göstergeler temelinde ölçülen değişkenler yardımıyla gözlenebilir. Psikoloji, sosyoloji, eğitim, ekonomi ve pazarlama gibi çoğu alanda asıl ilgilenilen kavramların doğrudan ölçülmesi bazen mümkün olmaz. Psikolojide, kişinin kendine bakış açısı ve motivasyon; sosyolojide, çaresizlik ve huzursuzluk; eğitimde sözlü yetenek ve eğiticinin beklentisi; ekonomi de ise davranışlar, müşteri memnuniyeti, kalitenin algılanışı gibi kavramlar gizil değişkenlere örnek olarak verilebilir. Sözü edilen gizil değişkenler gözlenemediği için doğrudan ölçülemezler. Bu yüzden, araştırmacı, gizil değişkeni işlemsel olarak tanımlamak için varsayılan yap1 açısından gizil değişkeni gözlenebilir değişkenlerle ilişkilendirmek zorundadır. (Cheng, 2001; Reisinger ve Turner, 1999).

YEM, ikinci nesil veri analiz tekniği olarak (Bagozzi ve Fornell, 1982), regresyon gibi birinci nesil istatistiksel tekniklere kıyasla, birçok bağımlı ve bağımsız değişkenler arasındaki ilişkilerin modellenmesi ile karmaşık bir araştırma problemini tek bir süreçte, sistematik ve kapsamlı bir şekilde ele almayı sağlamaktadır (Anderson ve Gerbing, 1988). Özellikle karmaşık modellerin testinde başarılı olduğu, birçok analizi bir defada yaptığ ilişkiler ağına yönelik varsa yeni düzenlemeler tavsiye ettiği, aracılık ve düzenleyicilik (moderasyon) etkilerini incelemeyi kolaylaştırdığı, ölçüm hatalarını hesaba katıyor olması gibi nedenlerle YEM, birçok teorinin test edilmesinde ve 
yeni modellerin geliştirilmesi sürecinde kullanılmakta olan bir yöntemdir (Dursun ve Kocagöz, 2010)

YEM, son yıllarda tüm dünyada popüler hale gelen bir istatistiksel analiz yöntemidir. Araştırmacının zihnindeki, araştırma henüz yapılmadan önce varolan değişkenler arası ilişkilere ait bir modelin, araştırmadan elde edilen veriler aracılı̆̆ 1 ile sinanmasına dayanmaktadır. Varyans analizi, MANOVA, faktör analizi, regresyon gibi daha alışılmış istatistiksel yöntemlerden en büyük farkı çok sayıda değişken arasındaki ilişkiyi modeller şeklinde inceleyebilmesidir. Buna göre, araştırmacı ilgilendiği değişkenlerin gerçek dünyada birbirleriyle olan ilişkilerini ve bu ilişkilerin yönlerini tanımlayan bir fikre sahiptir ve bu fikir temelde bir modeldir. Araştırmacı ilgilendiği değişkenlere ait ölçekleri kullanarak verileri toplar ve bu verilerin analizini kafasındaki ilişkiler doğrultusunda yapar. Yapısal eşitlik modeli bu analizin yapılabilmesine olanak sağlayan bir istatistiksel yöntemdir. (Ayyıldız ve Cengiz, 2006). Bu anlamda YEM, regresyon modelindeki değişkenler arasındaki nedensel yapısal ilişkiler ile faktör analizindeki gizli faktör yapılarını kapsamlı bir şekilde tek bir analizde birleştirmektedir. Diğer bir deyişle YEM, ortaya konan ilişkisel modellerin, faktör ve regresyon analizini bir arada kullanarak test edilebilmesini kolaylaştıran bir metodlar dizisidir. Çok değişkenli istatistik analizleri için geçerli olan temel varsayımlar bu teknikler için de doğal olarak geçerlidir.

$\mathrm{Bu}$ çalışmada, özel bir ilköğretim okulu öğrencisi velilerinin, okul hakkındaki düşüncelerini etkileyen faktörler araştırılmıştır. Bu bağlamda, uygulanan bir anket aracılığıyla elde edilen veriler analiz edilmiş, açıklayıcı faktör analizi kullanılarak okula olan bakış açısını etkileyen faktörler belirlenmiş ve YEM aracılığıyla bu faktörlerin etkileri ölçülmüş ve elde edilen sonuçlar değerlendirilmiştir. Çalışmanın sonraki bölümünde, faktör analizi ve YEM ile ilgili temel kavramlara kısaca değinilmiştir. Üçüncü bölümde ise özellikle YEM ile ilgili mevcut literatür özetlenmiştir. Çalışmanın dördüncü bölümünde, çalışmada uygulanan metodoloji ve elde edilen sonuçlar paylaşılmış olup, son bölümde genel bir değerlendirmede bulunulmuştur. 


\section{S.ALPAYKUT \\ 2. FAKTÖR ANALİZI VE YAPISAL EŞİTLİK MODELİ}

Faktör analizi; birbirleriyle ilişkili çok sayıdaki değişkeni az sayıda, daha anlamlı, kolay anlaşılabilir ve birbirinden bağımsız faktörler haline getiren ve yaygın olarak kullanılan çok değişkenli istatistik tekniklerinden biridir. Faktör analizi, özellikle, çok karmaşık ve çok boyutlu ilişki analiziyle karşılaşıldığ 1 durumlarda, kanonik korelasyon analizi, kümeleme analizi ve çok boyutlu ölçekleme analizi gibi kullanılabilecek bir yöntemdir (Albayrak,2006:86).

Faktör analizi açıklayıcı ve doğrulayıcı faktör analizi olmak üzere iki başlıkla açıklanabilir. Açıklayıcı Faktör Analizi (AFA) (Exploratory-Descriptive Factor Analysis EFA-DFA) çok sayıdaki değişkenin temel yapılarını ya da boyutlarını (faktörlerini) ortaya çıkarmak için yapılır. Burada değişkenler arasındaki ilişkiye dayalı olarak bir değişken her hangi bir faktörle ilişkili olabilir ve ondan etkilenerek yük alabilir. Dolayısıyla geleneksel faktör analizinde (AFA) belirli bir ön beklenti ya da deneme olmaksızın faktör ağırlıkları temelinde verinin faktör yapısı belirlenir. Doğrulayıcı Faktör Analizi (DFA) ise, belirli değişkenlerin bir kuram temelinde önceden belirlenmiş faktörler üzerinde ağırlıklı olarak yer alacağ 1 şeklindeki bir ön beklentinin test edilmesine dayanır. Bu nedenle, analizde yer alacak değişkenler hipotezler doğrultusunda seçilir ve bu değişkenlerin istenilen faktörlerde ne oranda yer aldıklarına bakılır. Genel faktör analizinde (AFA) kaç adet faktörün yer alacağı bilinmezken, DFA'da faktör sayısı kesin olarak belirtilir ve bu test edilir. Bunun en yaygın uygulama alanı, belirli maddelerin önceden belirlenmiş alt boyutlarda (gizli-gizil değişkenlerde) yer alması beklenen ölçeklerin (anketlerin) faktör yapısını incelemek ve doğrulamaya çalışmaktır

YEM ve Doğrulayıcı Faktör Analizi (DFA)(Comfirmatory Factor AnalysisCFA) temelde aynı mantığa ve hesaplama tekniğine dayanmasına karşın kullanımda farklı kavramlar olarak ele alınmaktadır. YEM yardımıyla genellikle bir modelin ya da bu modele alternatif diğer modellerin test edilerek karşılaştırılması yoluyla veriyi en iyi tanımlayan modelin belirlenmesi amaçlanır. $\mathrm{Bu}$ nedenle YEM, geleneksel regresyon modellerinin bir uzantısı olarak kabul 
edilebilir. DFA ise sosyal bilimlerde daha çok ölçek (anket) geliştirme ya da geçerlik analizlerinde kullanılmakta ve önceden belirlenmiş ya da kurgulanmış bir yapının doğrulanması ya da kabul edilmesi amacını taşımaktadır. DEA’ın kökeni geleneksel genel faktör analizlerine dayanır.

YEM, hem model kurma aşamasında hem de analiz aşamasında diğer çok değişkenli analiz yöntemlerinden ayrılmaktadır. YEM, çok sayıda bağımlı ve bağımsız değişken üzerinde analiz yapmaya imkan tanıyan çok değişkenli analiz yöntemlerinden farklı olarak gizli değişkenler arasındaki yapıyı ortaya çıkarmayı sağlar ve analiz esnasında normal verileri değil korelasyon veya kovaryans değerlerini kullanır. Yapısal eşitlik modelleri psikoloji ve ekonomi başta olmak üzere eğitim, pazarlama, sosyoloji gibi birçok alanda yaygın olarak kullanılmaktadır.

\subsection{Yapısal Eşitlik Modelinde Uyum İyiliği İndeksleri}

YEM'de model tahmininden sonra, modelin örnekleme ne kadar uyum sağladığı araştırılmalıdır. İlk olarak modelde belirlenmiş olan ilişkilerin anlamlı ve beklediği gibi olup olmadığına bakılır. Model tarafından belirtilmiş olan her bir ilişki beklendik çıktıysa bu durumda modelin uyum değerleri açısından istenen değeri üretip üretmediğine bakılır. İstenen değerler elde edilmişse bulgular yorumlanır (Şimşek, 2007: 70). Diğer bir ifade ile t istatistiği ile anlamlılıkları kontrol edildikten sonra, uyum değerleri için $\chi^{2}$ istatistiği ve uyum ölçütleri kullanılır.

Belirlenen modelin veriye ne kadar uyum sağladığını belirlemek için uyum iyiliği istatistiklerinden yararlanılır. Parametre anlamlılığ sinandıktan sonra modelin genel uygunluğu ve parametrelerin tek tek uygunluğu incelenir. Model uygunluğunun değerlendirilmesinde kullanılan birbirinden farklı uyum iyiliği indeksleri ve bu indekslerin sahip olduğu istatistiksel fonksiyonlar vardır. Önerilen indeksler arasında en çok kullanılanları: benzerlik oranı ki-kare istatistiği ( $\left.\chi^{2}\right)$, RMSEA (Ortalama hata karakök yaklaşımı -Root-mean-square error approximation), GFI (Uyum iyiliği indeksi -Goodness-of-fit index) ve AGFI 


\section{S.ALPAYKUT}

(Uyarlanmış uyum iyiliği indeksi-Adjusted Goodness-of-fit index) dir (Joreskog ve Sörbom, 1993).

Ortalama hataların karekökü ve Yaklaşık Hataların Ortalama Karekökü (Root Mean Square Error of Approximation, RMSEA) indeksleri gelir. Her iki indeks değerinin de GIF ve AGFI'nin tersine "0" yakın değerler vermesi (gözlenen ve üretilen matrisler arasında minimum hata olması) istenir. 0.05 'e eşit ya da daha küçük olan değerler mükemmel bir uyuma karşılık gelir. 0.05 ile 0.08 arasındaki değerler de modelin karmaşıklığı dikkate alınarak kabul edilebilir uyum değerleri olarak görülebilir.

İyi bir YEM analizde Ki-Kare değerine ek olarak mutlak ve artmalı uyum indeksleri grubundan indekslerin verilmesi önerilmektedir (Hoyle, 1995, 158-177). YEM analizinde kullanılan paket programlar farklı sayıda uyum indeksleri vermekte; bazen de aynı indeks farklı bir isimle verilmektedir. LISREL paket programını kullanan araştırmacılar, yayınlarında genellikle, Ki-Kare değeri yanında sıklıkla GFI, AGFI, RMSEA, CFI ve NNFI değerlerini de rapor etmektedirler.

\section{LITERATÜR}

Çalışmanın bu bölümünde, yapısal eşitlik modeli ile ilgili literatürde yer alan çalışmalar incelenmiş ve genel olarak özetlenmiştir.

Son yıllarda popülerliği artan YEM ile ilgili literatürdeki çalışmaların sayısında artış olmakla birlikte, çalışmaların olduğu alanların da farklılaştı̆g 1 görülmektedir. Yılmaz (2004) Eskişehir'deki vatandaşların alışveriş yaptıkları yerlerden şikayetlerinin belirlenmesi amacıyla YEM'den yararlanmıştır. Şahin vd (2008) ise çiftçilerin tarımsal üretimini etkileyen risk davranışlarının belirlenmesi amaçlı çalışmada YEM'i kullanmışlardır. Yeniçeri ve Erten (2008) ise YEM'den mağaza sadakat programları ile müșteri sadakati arasındaki ilişkiyi ölçmek amacıyla yararlanmışlardır. Kuvvetli vd. (2016) Türkiye'deki Altı Sigma projelerinin başarı düzeylerini etkileyen faktörlerin analizinde YEM'i kullanmışlardır. 
Genel olarak özetlemek gerekirse, YEM'in zeka, korku, başarı gibi kavramların gizil faktör olması sebebiyle psikoloji alanında, arz ve talep kavramlarının direkt ölçülemeyen yapısı sebebiyle ekonomi alanında, öğrenci davranışları, ders başarısı gibi kavramlardan dolayı eğitim sektöründe, kalite, müşteri memnuniyeti gibi direkt olarak ölçülemeyen değişkenlerden dolayı pazarlama alanında, çeşitli toplumsal olayların araştırılması dolayısıyla sosyoloji alanında sıklıkla ve başarılı bir şekilde kullanıldığı görülmektedir.

\section{METODOLOJi}

\subsection{Araştırmanın Amacı}

Son y1llarda oldukça farklı amaçlar doğrultusunda birçok başarılı YEM uygulaması literatürde yer almaktadır. Bu çalışmada da, özel bir ilköğretim okulunda okuyan öğrencilerin velilerinin, okuldan olan memnuniyetini etkileyen faktörlerin belirlenmesi amaçlanmıştır. Bu doğrultuda, İzmir'deki XYZ ilköğretim okulunda okuyan öğrencilerin velilerine uygulanmak üzere 22 sorudan oluşan bir anket tasarlanmış ve uygulanmıştır.

\section{2 Örneklem Seçimi}

Araştırmada herhangi bir örnekleme yöntemi kullanmak yerine, okulda okuyan tüm öğrencilere hazırlanan anket dağıtılmış ve öğrenci velilerinden anketi doldurmaları istenmiştir. Okuldaki öğrenci sayısı 220 olup, anketlerden 182 tanesi ( geri dönüş oranı \%83) geri dönmüştür.

Hazırlanan anketin Cronbach's alfa değeri 0,821 olarak elde edilmiş olup, bu değer anket güvenilirliğin oldukça yüksek olduğu şeklinde yorumlanabilir.

\subsection{Tanımlayıcı İstatistikler}

Ankette yer alan soruların ortalama, s.sapma, çarpıklık ve basıklık değerleri Tablo 1'de verilmiştir. Tablo 1 incelendiğinde, en yüksek ortalamanın sınıflardaki öğrenci sayısı ile ilgili olduğu görülmektedir. Benzer şekilde, sınıflarda öğrencilerin işitme kolaylığı ve ısınma imkanları, veliler tarafından en yüksek puanların verildiği sorulardır. Buna karşın, fotokopi imkanları ve kantindeki bekleme sırasındaki düzen, veliler tarafından en önemsiz bulunan konulardır. 


\section{S.ALPAYKUT}

Ankette yer alan sorular için çarpıklık ve basıklık değerleri incelendiğinde ise, tüm sorular için \pm 3 limitleri arasında kalındığı görülmektedir.

Tablo 1. Sorulara ait tanımlayıcı istatistikler

\begin{tabular}{|c|c|c|c|c|c|}
\hline No & Soru & Ortalama & S.Sapma & Çarpıklık & Basıklık \\
\hline 1 & $\begin{array}{l}\text { Kantindeki gıda ürünlerinin } \\
\text { sayısı }\end{array}$ & 3,42 & 1,13 & $-0,360$ & $-0,597$ \\
\hline 2 & $\begin{array}{l}\text { Kantindeki kırtasiye ürünlerinin } \\
\text { sayısı }\end{array}$ & 3,13 & 1,27 & $-0,142$ & $-0,881$ \\
\hline 3 & Kantini işletenlerin tutumu & 3,70 & 1,13 & $-0,526$ & $-0,625$ \\
\hline 4 & $\begin{array}{l}\text { Kantindeki bekleme sırasındaki } \\
\text { düzen }\end{array}$ & 2,97 & 1,12 & $-0,101$ & $-0,645$ \\
\hline 5 & Kantindeki ürünlerin fiyatı & 3,54 & 1,12 & $-0,426$ & $-0,668$ \\
\hline 6 & Yemekhane mönüsü & 3,80 & 1,17 & $-0,840$ & $-0,101$ \\
\hline 7 & Yemekhane sırasındaki düzen & 3,74 & 1,12 & $-0,537$ & $-0,752$ \\
\hline 8 & $\begin{array}{l}\text { Yemekhanedeki temizlik ve } \\
\text { hijyen }\end{array}$ & 4,12 & 0,99 & $-0,930$ & $-0,033$ \\
\hline 9 & Yemekhanedeki yemek miktarı & 4,09 & 1,09 & $-1,091$ & 0,338 \\
\hline 10 & Bilgisayarların yeterliliği & 4,16 & 1,01 & $-1,457$ & 2,025 \\
\hline 11 & Sinevizyonun yeterliliği & 3,86 & 1,14 & $-0,946$ & 0,194 \\
\hline 12 & Tepegözün yeterliliği & 4,13 & 1,04 & $-1,178$ & 0,805 \\
\hline 13 & Fotokopi imkanlarının yeterliliği & 2,65 & 1,45 & 0,302 & $-1,319$ \\
\hline 14 & Sinıf mevcudunun durumu & 4,59 & 0,71 & $-2,372$ & 2,402 \\
\hline 15 & Sınıflardaki ısınma imkanları & 4,48 & 0,79 & $-1,414$ & 1,168 \\
\hline 16 & Sınıflardaki dolap düzeni & 4,13 & 0,99 & $-1,321$ & 1,790 \\
\hline 17 & Sınıflardaki sıra düzeni & 4,13 & 1,13 & $-1,383$ & 1,195 \\
\hline 18 & $\begin{array}{l}\text { Sinıflardaki tahtayı görme } \\
\text { imkanı }\end{array}$ & 4,16 & 1,07 & $-1,452$ & 1,628 \\
\hline
\end{tabular}


Dokuz Eylül Üniversitesi İktisadi ve İdari Bilimler Fakültesi Dergisi

Cilt:32, Sayl:2, Yll:2017, ss. 355-368

\begin{tabular}{|l|c|c|c|c|l|}
\hline 19 & Sinıflarda işitme kolaylığı & 4,51 & 0,82 & $-2,047$ & 2,483 \\
\hline 20 & $\begin{array}{c}\text { Verilen ödevlerin öğrencilere } \\
\text { katkısı }\end{array}$ & 4,36 & 0,99 & $-1,819$ & 3,069 \\
\hline 21 & Verilen projelerin sayısı & 4,12 & 1,18 & $-1,391$ & 1,046 \\
\hline 22 & Verilen projelerin katkısı & 4,21 & 1,14 & $-1,498$ & 1,420 \\
\hline
\end{tabular}

Ankette yer alan sorulara ait tanımlayıcı istatistikler yapıldıktan sonra, soruların daha az sayıda faktör kullanılarak açıklanması amaçlanmıştır. KMO $(0,793)$ ve Bartlett's test (p:0,00) değerleri, soruların açıklayıcı faktör analizi için uygun olduğunu göstermektedir. Faktör analizi için gerçekleştirilen döndürülmüş bileşenler matrisi ve oluşturulan faktörlere ait istatistikler Tablo 2 ve Tablo 3'de gösterilmiştir.

Tablo 2. Döndürülmüş Bileşenler Matrisi

\begin{tabular}{|c|c|c|c|c|c|}
\hline \multicolumn{7}{|c|}{ Rotated Component Matrix } \\
\hline & \multicolumn{5}{|c|}{ Component } \\
\cline { 2 - 6 } & 1 & 2 & 3 & 4 & 5 \\
\hline s_1 &, 778 &, 169 &, 191 &, 070 &, 158 \\
\hline s_2 &, $\mathbf{8 1 4}$ &, 152 &, 044 &, 126 &, 122 \\
\hline s_3 &, $\mathbf{8 6 5}$ &, 125 &, 147 &, 082 &, 017 \\
\hline s_4 &, $\mathbf{8 5 5}$ &, 062 &, 079 &, 061 &,- 005 \\
\hline s_6 &, 691 &, 069 &, 162 &, 043 &, 080 \\
\hline s_7 &, 156 &, 855 &, 122 &, 091 &, 102 \\
\hline s_8 &, 120 &, $\mathbf{8 2 8}$ &, 162 &, 032 &, 071 \\
\hline s_9 &, 086 &, $\mathbf{8 5 0}$ &, 225 &, 078 &,- 027 \\
\hline
\end{tabular}


S.ALPAYKUT

\begin{tabular}{|r|r|r|r|r|r|}
\hline s_10 &, 039 &,- 211 &, 070 &, 003 &, $\mathbf{7 3 3}$ \\
\hline s_11 &, 101 &, 215 &, 067 &, 086 & $\mathbf{, 6 5 3}$ \\
\hline s_12 &, 064 &, 062 &, 143 &, 059 &, $\mathbf{6 9 9}$ \\
\hline s_13 &, 151 &, 243 &, 099 &, 150 &, $\mathbf{5 7 5}$ \\
\hline s_14 &, 047 &, 151 &, $\mathbf{3 9 6}$ &, 131 &, 020 \\
\hline s_15 &, 301 &, 111 & $\mathbf{, 6 2 0}$ &,- 086 &, 069 \\
\hline s_16 &,- 011 &, 289 & $\mathbf{, 5 3 7}$ &, 151 &, 093 \\
\hline s_17 &, 233 &, 200 &, $\mathbf{6 5 0}$ &, 099 &, 052 \\
\hline s_18 &, 058 &, 058 &, 751 &, 056 &, 011 \\
\hline s_19 &, 172 &, 061 &, $\mathbf{7 1 5}$ &, 176 &, 285 \\
\hline s_20 &,- 050 &, 071 &, 349 & $\mathbf{, 6 6 1}$ &, 189 \\
\hline s_21 &, 113 &, 106 &, 036 & $\mathbf{, 8 1 5}$ &, 093 \\
\hline s_22 &, 177 &, 007 &, 051 & $\mathbf{, 8 8 6}$ &, 011 \\
\hline
\end{tabular}

Tablo 3. Faktör tanımları ve istatistikler

\begin{tabular}{|l|c|c|c|c|}
\hline & Faktör & Sorular & Ortalama & Cronbach's $\alpha$ \\
\hline 1 & Kantin imkanları & s1,s2,s3,s4,s5 & 3,35 & 0,890 \\
\hline 2 & Yemekhane & s6,s7,s8,s9 & 3,94 & 0,903 \\
\hline 3 & Teknolojik imkanlar & s10,s11,s12,s13 & 3,70 & 0,648 \\
\hline 4 & Sinıf durumu & s14,s15,s16,s17,s18,s19 & 4,33 & 0,755 \\
\hline 5 & Ödev ve projeler & s20,s21,s22 & 4,23 & 0,783 \\
\hline
\end{tabular}

Tablo 3 incelendiğinde, en yüksek ortalamanın sınıfların durumu ile ilgili olduğu ve bu faktörü okulda verilen ödev ve projelerin izlediği görülmektedir. Her faktör için verilen Cronbach's alfa değerleri ise, faktörleri oluşturan soruların, 
faktörleri yansıtmada güvenilir olduğunu göstermektedir. Ayrıca, yukarıda yer alan 5 faktör, toplam değişkenliğin \% 79 'unu açıklamaktadır.

\subsection{Yapısal Eşitlik Modeli}

Açıklayıcı faktör analizi sonucu elde edilen faktörlere isim verildikten ve faktörler ile ilgili genel değerler incelendikten sonra, Lisrel 8.8 aracılı̆̆ıyla Yapısal Eşitlik Modeli (YEM) oluşturulmuştur. Elde edilen model Şekil 1'de verilmiştir. Modele göre, velilerin okuldan olan memnuniyetini açıklayan model aşağıdaki gibidir:

Memnuniyet $=0,28 *$ kantin imkanları $+0,32 *$ yemekhane $+0,39 *$ teknolojik imkanlar $+0,20 *$ sinıf durumu $+0,23 *$ ödev ve projeler

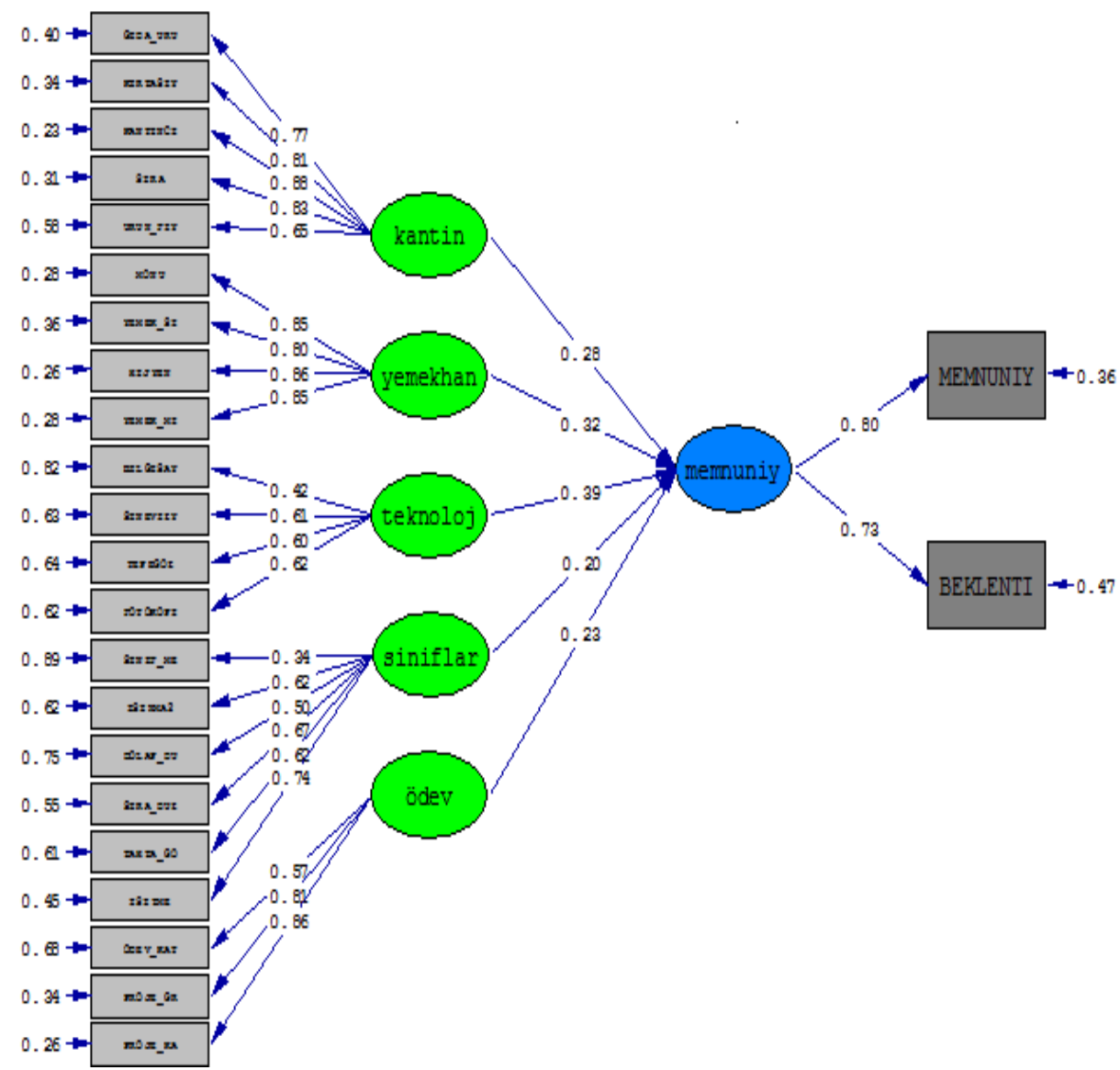

Şekil 1. Path Diyagramı 


\section{S.ALPAYKUT}

Path diyagramı incelendiğinde, velilerin, çocuklarının okudukları okuldan olan genel memnuniyetlerini en fazla etkileyen faktörün okulun teknolojik imkanları $(0,39)$ olduğu görülmektedir. Okulun teknolojik imkanlarını, okulun yemekhane $(0,32)$ ve kantini $(0,28)$ takip etmektedir. Genel memnuniyeti en az etkileyen faktörlerin ise öğrencilere verilen ödev ve projeler $(0,23)$ ile ders yapılan sınıfın durumu $(0,20)$ olması ise oldukça ilginçtir. Ayrıca, söz konusu iki faktörün de ortalama puanlarının en yüksek faktörler olması da dikkat çekici bir bulgudur.

Path diyagramının ölçüm modeli incelendiğinde ise, okulun teknolojik imkanları içerisinde sinevizyon, tepegöz ve fotokopi imkanının bulunmasının bilgisayar imkanlarına göre daha önemli olduğu görülmektedir. $\mathrm{Bu}$ bulgu, bilgisayarların artık çok yaygın olarak bulunmasının bir sonucu olarak düşünülebilir. Kantin imkanları açısından değerlendirildiğinde ise, gıda ürünlerinin sayısı ve ürünlerin fiyatı dışındaki etkenlerin daha önemli olduğu görülmektedir. Yemekhane faktörü içerisinde yer alan soruların yaklaşık olarak aynı öneme sahip olduğu görülürken, sınıflardaki işitme imkanları ve sınıflardaki sıra düzeninin, sınıf durumu açısından en önemli kriterler olduğu söylenebilir. Ödev ve projeler faktörü açısından değerlendirildiğinde ise, öğrenci velilerinin, projelerin ödevlere göre daha etkili olduğu görüşünde olduğu anlaşılmaktadır.

Oluşturulan modelin uyum iyiliği değerleri incelendiğinde, $\chi^{2} / d f$ değerinin 1,35, RMSEA değerinin 0,056, NFI'nin0,83, CFI'nin 0,92, GFI değerinin ise 0,85 olduğu görülmektedir. $\mathrm{Bu}$ değerler genel olarak modelin verilere oldukça iyi derecede uygun olduğunu göstermekle birlikte, daha kritik olan ve sıklıkla kullanılan $\chi^{2} / d f$ ve RMSEA değerleri, model uyumluluğunun üst düzey olduğuna işaret etmektedir.

\section{SONUÇ}

Son yıllarda ülkemizde özel okul sayısının artmasının bir sonucu olarak, bu sektördeki rekabet de artış göstermiş ayrıca öğrenci velilerinin de okul seçiminde daha seçici davranmasına sebep olmuştur. Birçok sektörde olduğu gibi bu sektörde de memnuniyet birçok farklı faktörün bir sonucu olarak ortaya çıkmaktadır. Bu 
çalışmada, son yıllarda kullanım alanı artış gösteren YEM kullanılarak, özel okullarda okuyan öğrencilerin velilerinin okuldan memnuniyet düzeyleri ölçülmeye çalışılmıştır. Bu doğrultuda İzmir'de faaliyet gösteren bir özel ilköğretim okulunda okuyan öğrencilerin velileri ile gerçekleştirilen anketten elde edilen veriler analiz edilmiştir. Öğrenci velilerinin okuldan olan memnuniyetlerini en fazla etkileyen faktörün okulun teknolojik imkanları olduğu görülmüştür. Öğrencilere verilen ödev ve projeler ile sınıfların durumundan olan memnuniyetin en yüksek puana sahip olmasına karşın, teknolojik imkanların en etkin faktör olması, çalışmada elde edilen önemli bir bulgudur. Ayrıca, velilerin okula bakış açısına göre okulun teknolojik imkanları, yemekhane ve kantininin öğrencilere verilen ödev ve projelere göre daha öncelikli olması da önemli bir sonuç olarak değerlendirilebilir.

\section{KAYNAKÇA}

ALBAYRAK, A.S. (2006), Uygulamalı Çok Değişkenli İstatistik Teknikleri, Asil Yayın Dağıtım, Ankara.

ANDERSON, J.C., GERBING D.W. (1988). "Structural equation modeling in practice: A review and recommended two-step approach”, Psychological Bulletin. 103(3),411-423.

AYYILDIZ H., CENGIZ E. (2006). "A conceptual investigation of structural equation models (SEM) on testing marketing models”, Süleyman Demirel University Journal of Faculty of Economics and Administrtive Sciences, 11(1), 63-84.

BAGOZZİ R.P. ve FORNELL, C. (1982). Theoretical concepts, measurement, and meaning, in A Second Generation of Multivariate Analysis, Praeger, New York, NY.

CHENG, E.W.L. (2001). "SEM being more effective than multiple regression in parsimonious model testing for management development research", Journal of Management Development, 20(7), 650-667. 


\section{S.ALPAYKUT}

DURSUN Y., KOCAGÖZ, E. (2010). "Structural equation modeling and regression: A comparative analysis", Erciyes University Faculty of Economics and Administrative Sciences, 35, s. 1-17.

HOYLE, R.H. (1995). Structural Equation Modeling: Concepts, Issues, and Application, SAGE Publications, London.

JORESKOG K. ve SÖRBOM, D. (1993). LISREL 8 User's Reference Guide; PRELIS 2 User's Reference Guide, Scientific Software International, Chicago.

KUVVETLİ, Ü., FİRUZAN, A.R., ALPAYKUT, S., GERGER, A. (2016). "Determining Six Sigma success factors in Turkey by using structural equation modelling”, Journal of Applied Statistics,43(4), 738-753.

REISENGER Y., TURNER L. (1999). "Structural equation modeling with Lisrel: Application in tourism”, Tourism Management, 20(1), 71-88.

ŞAHİN A., CANKURT M., MİRAN B. (2008) "Çiftçilerin Risk Davranışları: Bir Yapısal Eşitlik Modeli Uygulaması”, Dokuz Eylül Üniversitesi İktisadi ve İdari Bilimler Fakültesi Dergisi, 23(2), 153-172.

ŞİMŞEK, Ö. (2007). Yapısal Eşitlik Modellemesine Giriş: Temel İlkeler ve Lisrel Uygulamaları, Ekinoks Yayınları. Ankara.

YENIÇERI T., ERTEN E. (2008) "Mağaza Sadakat Programlarının Algılanması, Güven, İlişkiyi Sürdürme İsteği ve Mağaza Sadakati Arasındaki İlişkilerin Yapısal Eşitlik Modeli ile İncelenmesi”, Doğuş Üniversitesi Dergisi, 9 (2), 232247.

YILMAZ V. (2004). "Lisrel ile Yapısal Eşitlik Modelleri: Tüketici Şikayetlerine Uygulanmas1, Sosyal Bilimler Dergisi.32(8), 783-790. 